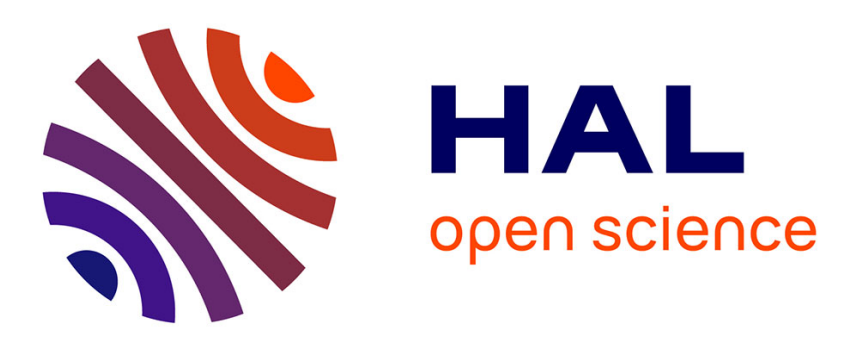

\title{
The ancient roots of nicotianamine: diversity, role, regulation and evolution of nicotianamine-like metallophores
}

Clémentine Laffont, Pascal Arnoux

\section{- To cite this version:}

Clémentine Laffont, Pascal Arnoux. The ancient roots of nicotianamine: diversity, role, regulation and evolution of nicotianamine-like metallophores. Metallomics, 2020, 12 (10), pp.1480-1493. 10.1039/D0MT00150C . cea-03125731

\section{HAL Id: cea-03125731 https://hal-cea.archives-ouvertes.fr/cea-03125731}

Submitted on 11 Feb 2021

HAL is a multi-disciplinary open access archive for the deposit and dissemination of scientific research documents, whether they are published or not. The documents may come from teaching and research institutions in France or abroad, or from public or private research centers.
L'archive ouverte pluridisciplinaire HAL, est destinée au dépôt et à la diffusion de documents scientifiques de niveau recherche, publiés ou non, émanant des établissements d'enseignement et de recherche français ou étrangers, des laboratoires publics ou privés. 


\section{The ancient roots of nicotianamine: diversity, role, regulation and evolution of nicotianamine-like metallophores.}

Clémentine Laffont, Pascal Arnoux

Aix Marseille Univ, CEA, CNRS, BIAM, Saint Paul-Lez-Durance, France F-13108. E-mails : clementine.laffont@gmail.com ; pascal.arnoux@cea.fr

ORCID :

C. Laffont : 0000-0003-3067-1369

P. Arnoux: 0000-0003-4609-4893

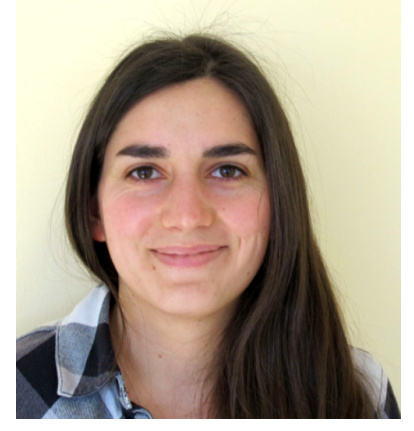

Clémentine Laffont
Clémentine Laffont obtained a master's degree in environmental microbiology at Université de Pau et des Pays de l'Adour (France). Since 2017, she continued as a PhD student

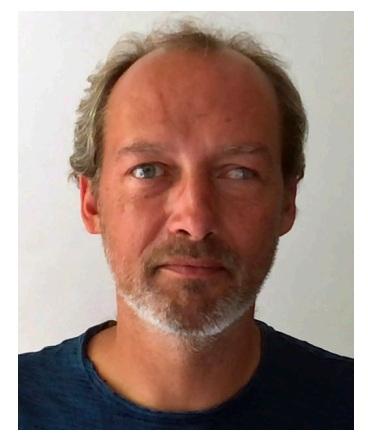

Pascal Arnoux
Pascal Arnoux received his $\mathrm{PhD}$ from the University of Paris XI, Orsay (France) in 2000. After postdoctoral positions at Toronto University (Canada) and at the CEA Cadarache (France), he obtained a

under the supervision of Pascal Arnoux at permanent position at the CEA in the the Molecular and Environmental Molecular and Environmental Microbiology Microbiology (MEM) team at the CEA - (MEM) team. His major interests focus on BIAM (Cadarache) and Aix-Marseille NA-like metallophore biosynthetic University. Her research is focusing on the machineries and the structural biology of nicotianamine-like metallophores.

metalloproteins and enzymes. 


\begin{abstract}
:
Nicotianamine (NA) is a metabolite synthesized by all plants in which it is involved in the homeostasis of different micronutrients such as iron, nickel or zinc. In some plants it also serves as a precursor of phytosiderophores that are used for extracellular iron scavenging. Previous works have also established the presence of NA in filamentous fungi and some mosses whereas an analogue of NA was inferred in an archaea. More recently, opine-type metallophores with homology to NA were uncovered in bacteria, especially in human pathogens such as Staphylococcus aureus, Pseudomonas aeruginosa or Yersinia pestis, synthesizing respectively staphylopine, pseudopaline and yersinopine. Here, we review the current state of knowledge regarding the discovery, biosynthesis, function and regulation of these metallophores. We also discuss the genomic environment of the cntL gene, which is homologous to the plant NA synthase (NAS) gene, and plays a central role in the synthesis of NA-like metallophores. This reveals a large diversity of biosynthetic, export and import pathways. Using sequence similarity networks, we uncovered that these metallophores are widespread in numerous bacteria thriving in very different environments, such as those living at the host-pathogen interface but also in the soil. We additionally established a phylogeny of the NAS/cntL gene and, as a result, we propose that this gene is an ancient gene and NA, or its derivatives, is an ancient metallophore that played a prominent role in metal acquisition or metal resistance. Indeed, our phylogenetic analysis suggests an evolutionary model where the possibility to synthesize this metallophore was present early in the apparition of life, although it was later lost by most living microorganisms, unless facing metal starvation such as at the host-pathogen interface or in some soils. According to our model, NA then re-emerged as a central metabolite for metal homeostasis in fungi, mosses and all known higher plants.
\end{abstract}




\section{Introduction}

NA was first discovered in 1971 in the plant Nicotiana tabacum (hence its name) partly due to its relatively high concentration. ${ }^{1}$ Its primary structure was determined a few years later, although its function in the plant remained unknown ${ }^{2}$. It is composed of an azetidine ring followed by two aminobutyrate moieties (Figure 1). It was not until the works on a plant's mutant called chloronerva that the link was made between NA and the phenotype of this mutant (retarded growth, intercostal chlorosis of young leaves and infertility). Indeed, it was known that a mixture of whole plant extract, even coming from other species, or grafting with a wild type plant was able to normalize this phenotype. At that time there was a quest to identify the "normalizing factor" i.e. the molecule that would restore the normal phenotype. The establishment of NA as the normalizing factor marked the beginning of numerous researches on the function and the role of NA in plants ${ }^{3,4}$. Since then, there is an abundant literature on NA and the few following points try to summarize some of the key findings with regard to its chemical property, function, transport and biosynthesis (for a review see reference 5):

(i) establishment of its metal binding properties ${ }^{6-8}$. It displays high affinity for all the micronutrients and form complexes with many divalent ions: $\mathrm{Cu}^{2+}, \mathrm{Ni}^{2+}, \mathrm{Co}^{2+}, \mathrm{Zn}^{2+}$, $\mathrm{Fe}^{2+}$ and $\mathrm{Mn}^{2+}$, and also forms a high affinity complex with $\mathrm{Fe}^{3+}$ (Figure 1)

(ii) its biological importance in the homeostasis of iron, copper, nickel and zinc ${ }^{9-14}$ and its role in the establishment of symbiotic nitrogen fixation nodules ${ }^{15}$

(iii) biotechnological significance of the NA level in hyperaccumulating plants and fortified food. Plants with high NA level are much more resistant to toxic level of nickel and might therefore be used for phytoremediation ${ }^{16-18}$; high NA level is also associated with a higher tolerance to iron deprivation and leads to iron and/or zinc fortified food ${ }^{19-}$ 23

(iv) establishment of how metal-NA complex is transported through specialized transporters of the Yellow Stripe Like (YSL) family ${ }^{24-26}$

$(v)$ discovery of how NA is synthesized by an enzyme called nicotianamine synthase (NAS). ${ }^{27-29}$ The reaction mechanism of NAS has attracted some interest since this enzyme catalyzes the condensation of three molecules of S-adenosylmethionine (SAM) in, apparently, a single step.

\begin{tabular}{|c|c|c|c|c|c|c|c|c|c|}
\hline \multirow{2}{*}{ Name } & \multirow{2}{*}{ Structure } & \multicolumn{7}{|c|}{$p K_{d}$} & \multirow[b]{2}{*}{ Ref. for $\mathrm{p} K_{\mathrm{d}}$} \\
\hline & & $\mathrm{Fe}^{3+}$ & $\mathrm{Cu}^{2+}$ & $\mathrm{Ni}^{2+}$ & $\mathrm{Co}^{2+}$ & $\mathrm{Zn}^{2+}$ & $\mathrm{Fe}^{2+}$ & $\mathrm{Mn}^{2+}$ & \\
\hline Nicotianamine & & 20.6 & 18.6 & 16.1 & 14.8 & 14.7 & 12.1 & 8.8 & Ref. 94 \\
\hline Staphylopine & & & 19.0 & 16.4 & 15.1 & 15.0 & 12.3 & 9.1 & Ref. 35 \\
\hline \multicolumn{10}{|l|}{ Yersinopine } \\
\hline \multicolumn{10}{|l|}{ Bacillopaline } \\
\hline Pseudopaline & & & 19.4 & 16.6 & 16.1 & 15.8 & 13.1 & 10.4 & Ref. 54 \\
\hline EDTA & & 25.1 & 18.8 & 18.4 & 16.4 & 16.5 & 14.3 & 13.9 & Ref. 95 \\
\hline
\end{tabular}

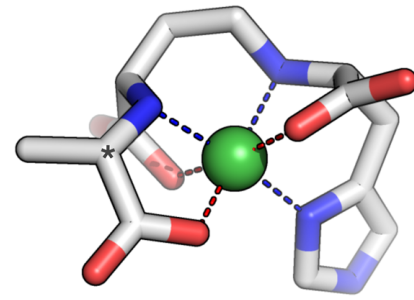

3D structure of staphylopine in complex with $\mathrm{Ni}^{2+}$ (ref. 44)

Figure 1: Structure and stability constant of NA and NA-like metallophores discussed in this review with metals, and comparison with EDTA. The chemical structures are colored according to the building blocks from which they are made, with the aminobutyrate from SAM (in black), L- and D-histidine (green and red, respectively), and pyruvate and $\alpha$-ketoglutarate (blue and fuchsia, respectively). The 3D structure 
of staphylopine- $\mathrm{Ni}^{2+}$ is shown on the right, which is taken from the structure of the CntA Periplasmic Biding Protein in complex with staphylopine. Note that bona fide staphylopine has an opposite stereochemistry at the carbon atom marked by an asterisk.

Outside the plant kingdom where the gene coding for NAS is ubiquitous, its presence was inferred in a few fungi, owing to the growing number of full genome sequencing. So far it was studied in more detail in the filamentous fungi Neurospora crassa. ${ }^{30}$ In this fungus, NA was detected and it was found that the transcript level of the gene coding for NAS was strongly upregulated in Zn-limiting conditions, hence its proposed role in Zn homeostasis. A gene coding for a NAS is also present in the moss Physcomitrella patens, which is the only known genome from the branch of bryophyte. ${ }^{31}$ In this case however, the presence of NA and its role have not yet been studied, although it would be interesting since this species is an important intermediate in the evolution toward the conquest of the land. The presence of a NAS gene in some archaea was noticed early ${ }^{27,30}$ but was not studied until the works described below.

Indeed, for still unknown reason, in-vitro study of a NAS enzyme from eukaryotic origin is challenging and, in this context, a distantly related enzyme from an archaea, which shares less than $20 \%$ sequence identity with a plant enzyme was investigated. ${ }^{32-34}$ Solving the three-dimensional structure of such an enzyme from $M$. thermotautrophicus (MtNAS) revealed an original fold composed of an N-terminal helix bundle combined with a Rosmann fold. Unexpectedly, it was shown that the protein co-purified and cocrystallized with its product. More interestingly, this product was not NA but a related molecule, the only difference being the replacement of the azetidine ring of NA by a glutamate moiety in the novel molecule. This molecule was called thermoNicotianamine (tNA) and it was verified that tNA was synthesized in vitro from two molecules of SAM and one molecule of glutamate. ${ }^{33}$ On the basis of the three-dimensional structure of MtNAS, a mutant that was free of its product was designed and its structure solved in the apo- form and in complex with substrates (SAM, glutamate and a combination of both). Combined with a following study, a realistic reaction mechanism was proposed in which a double translocation of the substrate and reaction intermediate take place at a single active site. ${ }^{33,34}$ Chemical synthesis of the reaction intermediate and three-dimensional structure of the complex with the enzyme confirmed the proposed translocation model and further extended the comprehension of this finely tuned reaction mechanism. ${ }^{34}$

All these structural works indicated that archaea possess an enzyme that is able to synthesize a molecule related to NA. However, the difficulties to study an archaea like $M$. thermautotrophicus are such that we are still lacking experimental tools to investigate the functional role of tNA in vivo. Indeed, the genetic manipulation of archaea is still challenging and the culture in defined media, a prerequisite for the study of metal homeostasis, is also lacking. Altogether, although this tNA molecule is able to bind various metals $(\mathrm{Cu}, \mathrm{Fe}, \mathrm{Ni}$ and $\mathrm{Co}$ ) with significant affinities, there are numerous unanswered questions such as whether or not tNA is synthesized in vivo, whether it is secreted or not, what is the target metal to be chelated and transported, and there is still no clue about the role it fulfils in vivo, i.e. if it is important for metal acquisition, homeostasis or resistance. The above-mentioned structural work on an archaeal NAS-like enzyme however revealed the catalytic residues and predicted the production of a nicotianamine-like metallophore in S. aureus, which was later confirmed experimentally. ${ }^{35}$ The discovery of nicotianaminelike metallophores in bacteria is interesting for several reasons, and the present review will describe the recent literature on this subject, from their discovery to their diversity, their function, how they are regulated and how these systems might have evolved. 


\section{Discovery of a nicotianamine-like metallophore in S. aureus}

Recently, the discovery and functional characterization of a set of biosynthetic genes coding for the biosynthesis of a nicotianamine-like metallophore called staphylopine in $S$. aureus extended the occurrence of a NAS homologue to the bacterial kingdom. ${ }^{35}$ Indeed, this NAS homologue (named $c n t L$ ) possesses the characteristics of a true NAS with a typical two-domains organization combining a N-terminal helix bundle followed by a Rossmann domain. Additionally, structure-based alignment showed that most of the conserved residues were clustered in the active-site cavity of the enzyme, an indication that this gene indeed belongs to the NAS family. In S. aureus, the cntL gene is located in the middle of two other genes ( $c n t K$ and $c n t M$ ), for which a combination of bioinformatic studies with biochemical, metabolomics and microbial approaches were detrimental to determine their function. Overall, this led to the establishment of a biosynthetic pathway where $\mathrm{CntK}$, a histidine racemase, catalyzes the reversible conversion of L-histidine into D-histidine, CntL, the NAS-like enzyme, ensures the transfer of a single aminobutyrate moiety from SAM onto the D-histidine substrate to form a pathway intermediate (noted xNA), and finally CntM, an enzyme belonging to the opine dehydrogenase family, catalyzes the reductive condensation of xNA with pyruvate, consuming a NADPH molecule and producing the metallophore staphylopine (Figure 2). CntM, the enzyme catalyzing this last step of $\mathrm{N}$-(carboxyalkyl)amino acids formation, is found across phylogenetically diverse organisms in which, briefly, it serves to propel mollusk invertebrates, induces plant's tumors for promoting bacterial growth or participates in amino acid biosynthesis ${ }^{36}$.

\section{Diversity of nicotianamine-like bacterial metallophores}

After the discovery of staphylopine, other nicotianamine-like metallophores were described, uncovering an unexpected diversity. In P. aeruginosa, the production of a nicotianamine-related molecule was hinted from a microbiological study focused on the response to zinc starvation. ${ }^{37}$ Very soon afterwards, two independent studies, one using purely biochemical approaches, the other using analytical, biochemical and microbiological approaches, identified this molecule as pseudopaline ${ }^{38,39}$. Pseudopaline differs from staphylopine in that it is made from a L-histidine in place of D-histidine as well as it incorporates an $\alpha$-ketoglutarate moiety instead of a pyruvate. In $Y$. pestis, the same biochemical approaches uncovered the production of yersinopine, which incorporates L-histidine and pyruvate. ${ }^{40}$ Regarding this diversity, one question was therefore to decipher its genetic and molecular basis, i.e. what were the reasons that led to the incorporation of L- $v s$ D-histidine, and pyruvate $v s \alpha$-ketoglutarate. This question was addressed recently, which led to the establishment of two simple rules: ${ }^{41}$

1. The occurrence of a cntK gene, encoding a histidine racemase homolog, lead to the incorporation of a D-histidine moiety in the final metallophore. In the absence of this gene it is L-histidine that is incorporated

2. The nature of the residue 150 in CntM ( $S$. aureus numbering) dictates the $\alpha$ ketoacid substrate specificity: an aspartate leads to the incorporation of pyruvate, whereas an alanine leads to the use of $\alpha$-ketoglutarate.

These two rules predicted the occurrence of a fourth metallophore, made of D-Histidine, SAM and $\alpha$-ketoglutarate, which was indeed produced by the biosynthetic genes of 
Paenibacillus mucillaginosus and called bacillopaline ${ }^{41}$. This diversity of bacterial nicotianamine-like metallophores highlights the bacterial need to produce specific metallophore, most probably to avoid its recovery by competing microorganisms.

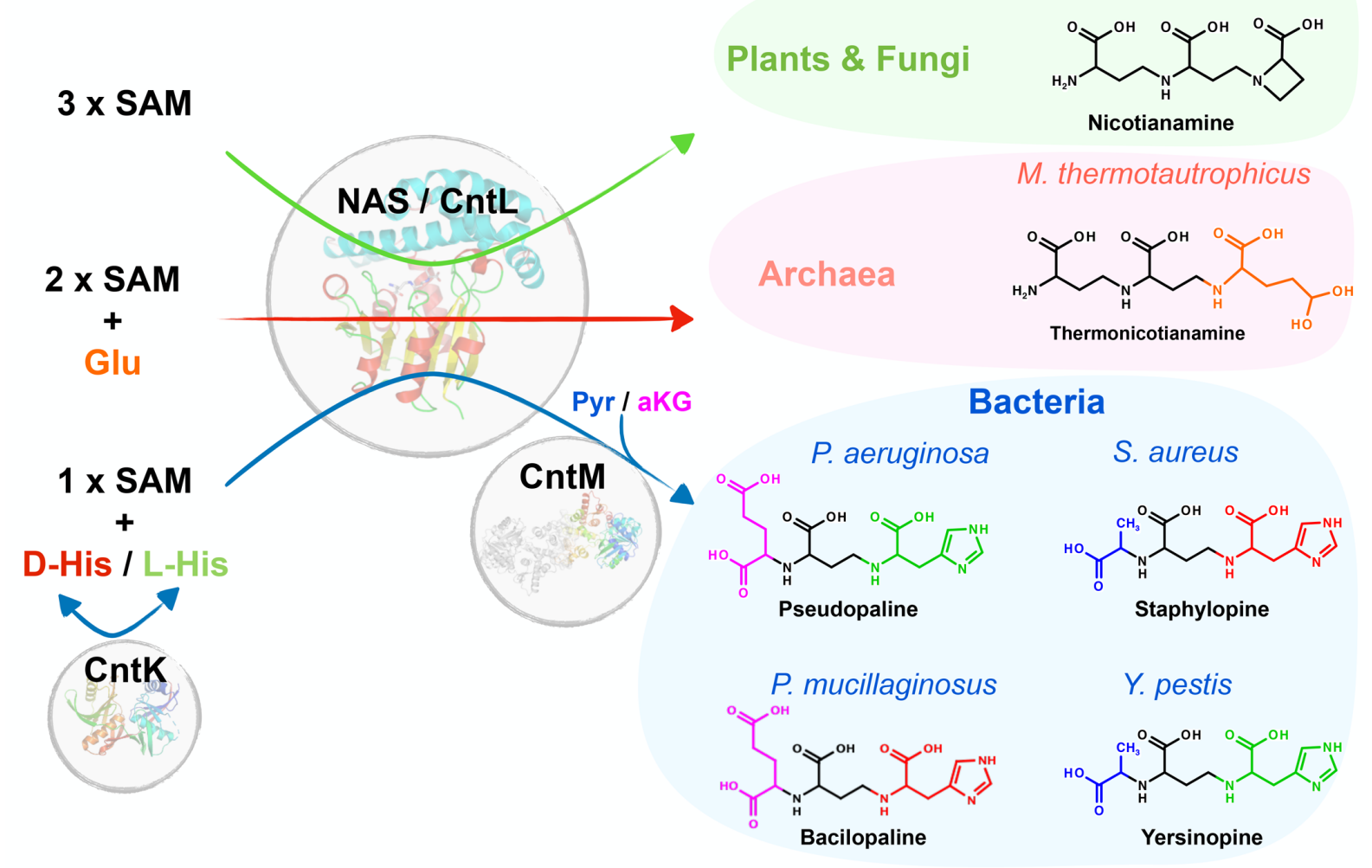

Figure 2: Diversity of nicotianamine-like metallophores in plants, archaea and bacteria. In plants, nicotianamine is synthesized from three SAM substrate molecules, from which only the aminobutyrate moiety (in black) is used. In archaea, two such aminobutyrate moiety are combined with glutamic acid to form tNA. In bacteria, L- or D-histidine (when CntK is present) are combined with a single aminobutyrate moiety from SAM by the NAS/CntL enzyme, and the pathway intermediate thus formed is combined with an $a$-ketoacid that is either pyruvate or $\alpha$-ketoglutarate. The structures of the biosynthetic enzymes are taken from ref. 33,42,43 for respectively CntL (from an archea), CntK and CntM (from S. aureus).

All these metallophores, from nicotianamine to bacterial nicotianamine-like metallophores, share the common feature of three nitrogen atoms, separated by three carbon atoms and decorated by at least three carboxylates (Figure 2). These conserved three nitrogen atoms and carboxylate groups are all participating in the chelation of a metal, as can be seen in the crystal structure of mugineic acid in complex with cobalt 44,45 or staphylopine-metal chelates in complex with its substrate binding protein. ${ }^{46}$

\section{Role of nicotianamine-like metallophore in bacteria}

The role of nicotianamine-related metallophores has mainly been studied in S. aureus and in P. aeruginosa, two clinically relevant human pathogens. Although staphylopine was not recognized at the time, the involvement of its transport pathway (initially named cnt for cobalt and nickel transport and composed of $c n t A B C D F$ ) in nickel and cobalt import was revealed. ${ }^{47}$ In this same study, it was shown that this import pathway was important for virulence in a mouse model of infection. The identification of staphylopine led to a reevaluation of the cnt operon, which was shown to include the biosynthetic genes (cntKLM) 
upstream the transport genes, and a gene involved in staphylopine export (cntE) downstream. ${ }^{35}$ Using various type of growth media and metal-starving conditions it was realized that staphylopine was playing a role in iron, zinc and copper import, in addition to its role in nickel and cobalt import ${ }^{35}$. Its role in zinc uptake was later confirmed in the context of nutritional immunity, where staphylopine was shown to compete with human calprotectin for zinc binding and import by $S$. aureus ${ }^{48}$. As already mentioned above, the $c n t E$ gene was shown to be responsible for staphylopine export, before its metal-complex

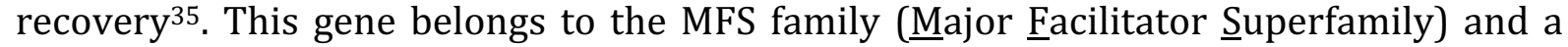
systematic evaluation of this gene family in $S$. aureus found that it was involved in the fitness of $S$. aureus ${ }^{49}$. It was also recently recognized that it was the intracellular staphylopine accumulation which led to a fitness defect in this mutant lacking cntE.50,51 Because metal accumulation and metal transporter expression are not affected when this mutant is compared to the wild-type strain one study proposed that toxicity of intracellular staphylopine accumulation was independent of its metal chelation properties. ${ }^{51}$ However, it is still not clear how this chelation-independent mechanism fits with the accumulation of a metallophore with such high affinity for metals. If the total metal concentration is not affected, it might rather be the intracellular metal speciation that is altered, which would mislead the cell as to the status of its intracellular metal content. This question may therefore need further investigations using techniques that would probe metal speciation within the cell.

In P. aeruginosa there was two strong indications that pseudopaline played a role in the fitness of the bacteria at the host-pathogen interface. First, a transcriptomic study indicated that the predicted cnt operon (though at the time not known to produce and recover pseudopaline) was highly expressed in human burn wounds.52 Second, a study of the growth of $P$. aeruginosa in Airway Mucus System (AMS) showed the overexpression of the PA4834 (within the same $c n t$ operon) and, most of all, showed that the growth of a mutant lacking this gene was impaired in AMS. ${ }^{53}$ Later, it was shown that PA4834 (named cntl) was encoding for the protein involved in pseudopaline export into the periplasm. ${ }^{38}$ The cnt operon (cntOLMI) in P. aeruginosa encode for a TonB-dependent transporter (cntO), two biosynthetic genes ( $c n t L M$ ) and an inner membrane exporter (cntl). Here also, lack of the exporter CntI led to increased intracellular concentration of pseudopaline, which was the most probable cause of its growth defect ${ }^{38}$. In zinc-poor growth media, only the double mutant lacking both znuABC and cntO or cntL (called zrmA and zrmB, respectively, although we prefer to use the cnt denomination as it offers the opportunity to keep consistent names and to compare operonic structures across species, vide infra) decreased the ability of $P$. aeruginosa to grow and compromised zinc accumulation. ${ }^{37}$ However, in a highly chelating environment, the single mutant lacking cnt $L$ revealed such a compromised zinc accumulation, highlighting the importance of this pathway in these conditions. ${ }^{38}$ Most of these studies have benefited and will continue to benefit from the input of chemists who not only produce nicotianamine-like molecules $35,54,46,55-57$, but also contribute to their characterization and possible modifications to better understand their mode of action in vivo, as was recently reported for pseudopaline. ${ }^{56}$ Recently, the complete export pathway of pseudopaline toward the extracellular space was determined and shown to be mediated by CntI for the crossing of the inner membrane, and also required the efflux pump MexAB, which exports pseudopaline from the periplasm to the extracellular space..$^{58}$ 


\section{Regulation of nicotianamine-like metallophore in bacteria}

Regulations of metal uptake systems in bacteria usually rely on repressors that respond to intracellular metal level. Such well characterized repressors bind to the promotor in their metal-bound state, repressing transcription of the downstream genes involved in metal uptake, and a decrease in intracellular metal concentration triggers a conformational change that prevent repressor-DNA interaction, relieving transcription of metal uptake pathways. These repressors are specific to a given metal, with Fur, Zur, Mur and Nur responding specifically to iron, zinc, manganese and nickel respectively. ${ }^{59}$

Transcriptional regulation of the cht operon has been studied in both P. aeruginosa and $S$. aureus (Figure 3). In $P$. aeruginosa, a mutant lacking the ZnuA permease involved in free zinc uptake revealed overexpression of zinc regulated genes, including the cht operon. ${ }^{60}$ It was latter shown that regulation of the $c n t$ operon was indeed controlled by Zur through intracellular zinc level. ${ }^{38}$ A mutant lacking the Zur repressor did not repressed cnt expression, and neither other metal other than zinc did exerted repression of cnt expression. This rather simple situation contrasts with what was found in S. aureus. In this bacteria there is a double regulation, orchestrated by both Fur and Zur, and this regulation is different whether it is exerted on the genes encoding staphylopine biosynthesis or the ones involved in its transport. ${ }^{61}$ Indeed, upstream the biosynthetic genes the promoter contains a Fur box followed by a Zur box, leading to an additional regulation, whereas upstream the transport genes there is an internal promoter with a Fur box superimposed to a Zur box, which lead to a cooperative regulation. Overall, this leads to a differential regulation scheme of the cht operon in which the biosynthetic genes are tightly regulated by either zinc or iron level (either one are sufficient to exert their regulatory activity) whereas the transport genes are more loosely regulated and require zinc and iron (the regulation is cooperative and the action of one repressor is enhanced by the presence of the other). Because once secreted staphylopine is a common good, one possible reason of this rather complex regulation scheme is that in particular conditions it would enhance staphylopine-metal recovery rather than producing de novo staphylopine. 


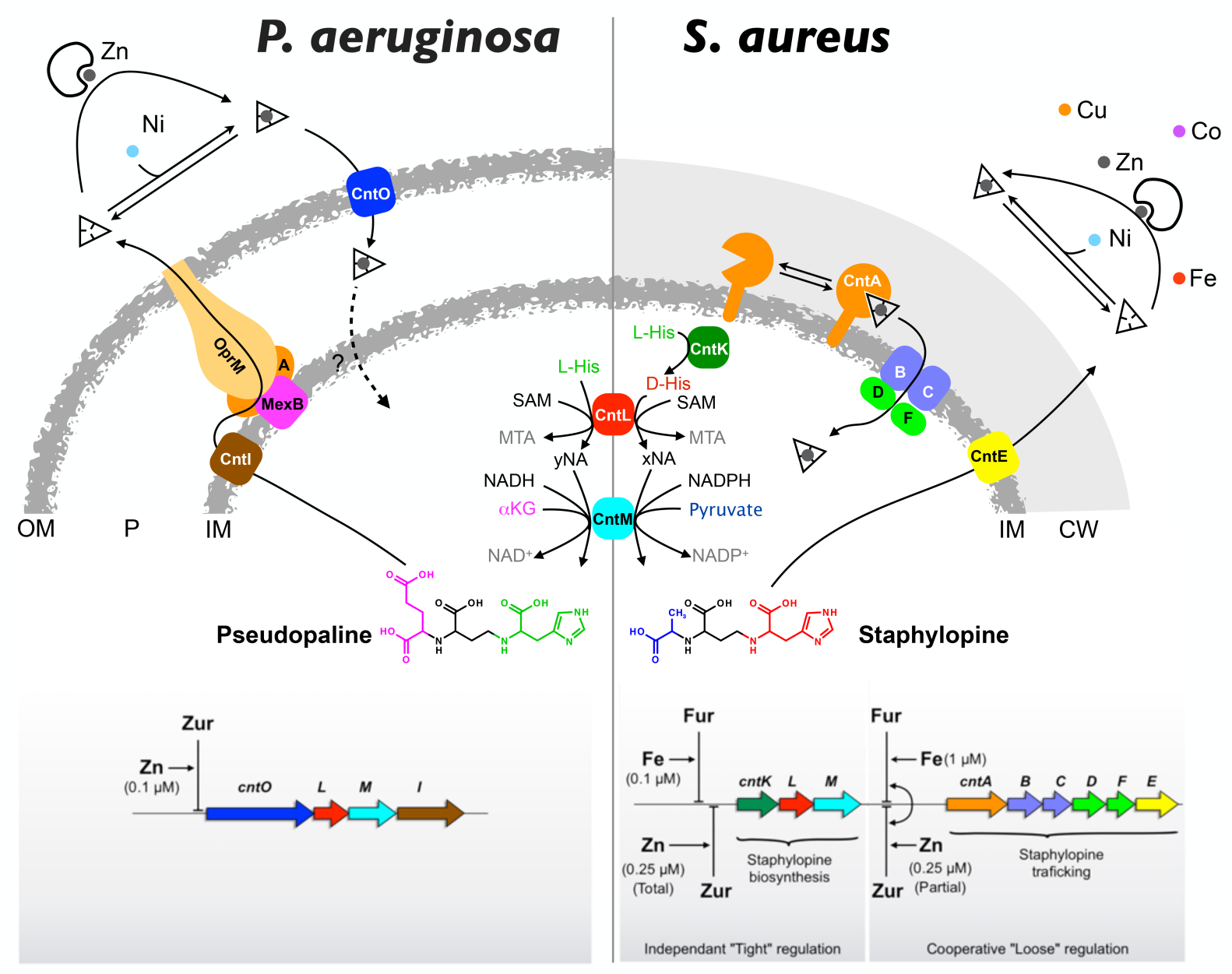

Figure 3: Model of nicotianamine-like metallophore production, trafficking (top) and regulation (bottom) in $\boldsymbol{P}$. aeruginosa and $\boldsymbol{S}$. aureus. Whereas the cht pathway and its regulation is rather well established in the case of $S$. aureus, a few question marks remain for $P$. aeruginosa, such as the fate of pseudopaline when it is imported as a metal complex and how metals are imported within the cell, i.e. whether it is the metal alone or in complex with pseudopaline that is imported.

Another level of regulation could also be exerted at the post-transcriptional level. Indeed, it was found that staphylopine biosynthesis by CntM is inhibited by an excess of metal. ${ }^{43}$ In fact, certain metals appeared to activate staphylopine biosynthesis (manganese) whereas nickel and cobalt were inhibitors and zinc and copper were activators of staphylopine production at low concentration and inhibitors at higher concentration. This level of regulation depends on both the concentration of xNA (the precursor of staphylopine) and the concentration of metal. This study was however recently challenged, arguing that metal regulation was due to metal binding to xNA substrate solely and not to the enzyme. ${ }^{55}$ Further studies are needed to clarify this issue, and, in particular, efforts should be made to try to evaluate the effect of buffers used by different authors, with high concentrations of citrate and Tris buffers in some studies. It is possible that the chelating properties of citrate and Tris could indeed mask subtle effects on this key step in staphylopine biosynthesis. Whether these regulatory mechanisms of activation and/or inhibition also occur in vivo remain to be determined, and they might take place in conditions where the concentration of metal suddenly changes, allowing a quick adjustment of staphylopine production to the internal metal level. 


\section{Clustering of the NAS/cntL gene family and their genomic environment}

Overall, there is a clear indication of the diversity of nicotianamine-like metallophores in the three kingdoms of life: eukaryotes, archaea and bacteria. A useful way to decipher this diversity is to use sequence similarity network (SSN) and visualize clusters by network visualization. ${ }^{62,63}$ The advantage of this analysis is that it somehow recapitulates a phylogenetic tree and could combine easier visualization for large datasets. Focusing on the NAS/CntL family (InterPro IPR004298), which is the conserved protein across all the nicotianamine and nicotianamine-like metallophores, we built such a SSN, which revealed some interesting features (Figure 4). Maybe the most striking feature is that eukaryotic, bacterial and archaeal proteins each form distinct clusters, with some clear outgroups, i.e. a few bacteria clustering within the eukaryote cluster and a few bacteria clustering within the archaeal cluster. This scheme suggests an ancient origin of this NAS/CntL family (vide infra) and also seems to recapitulate the metallophore diversity observed within each kingdom: a large diversity in the bacterial branch reflected by a few clusters, and a limited diversity within the eukaryote and archaeal kingdoms that are regrouped in only one or two clusters, respectively.

A

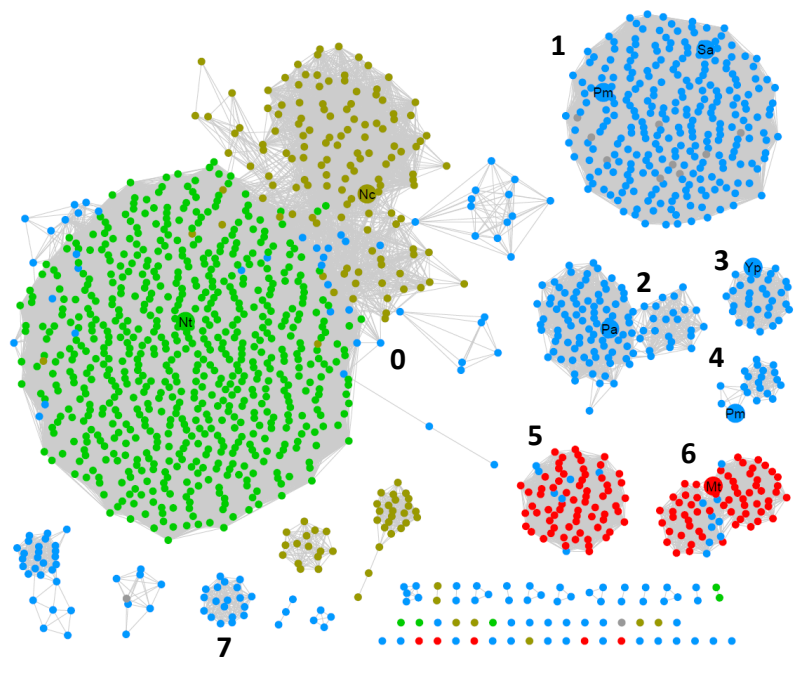

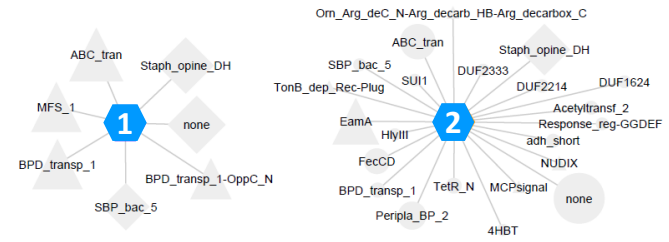

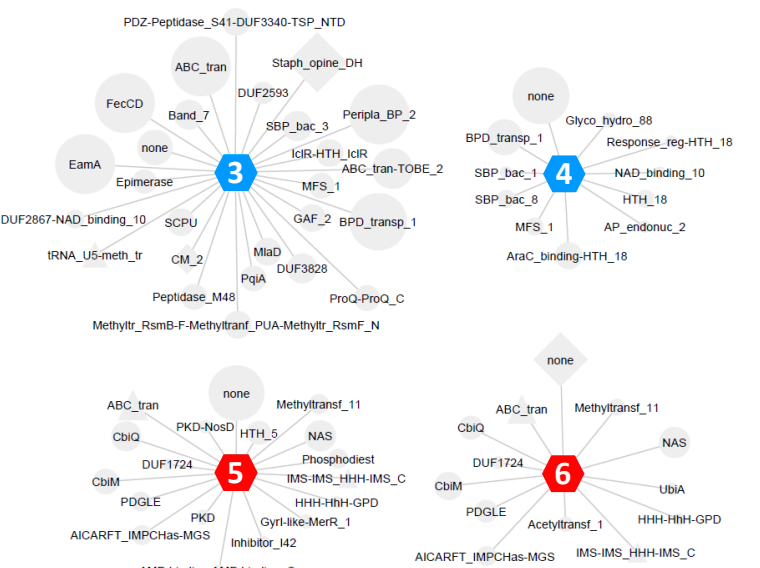

Figure 4: Sequence Similarity Network (SSN) of the NAS/CntL family and genomic environment within different clusters. (A) Sequence similarity network of the NAS/CntL family inferred using the InterPro \#004298 set of sequences. A minimum length of 240 residues together with a sequence similarity cutoff of $40 \%$ were applied to separate the clusters. Archaea, Bacteria, Eukaryotes and Fungi are depicted in red, blue, green and khaki green, respectively. Model species studied for their NA-like production are highlighted by larger dots: Nt for Nicotiana tabacum, Nc for Neurospora crassa, Mt for Methanothermobacter thermotautrophicus, Sa for Staphylococcus aureus, Pa for Pseudomonas aeruginosa, Yp for Yersinia pestis, and Pm for Paenibacillus mucilaginosus. (B) Genome neighborhood network associated with SSN clusters 1 to 6 , with SSN cluster-hub nodes and Pfam family spoke nodes. Co-occurrence frequencies of $20 \%$ and $+/-10$ open reading frames neighborhood are specified.

Interestingly, we confirmed a large representation of bacterial pathogens $(S$. aureus, $P$. aeruginosa, and $Y$. pestis as well as Fusobacterium varium, another human pathogen, Arsenophonus nasoniae, a wasp parasite and Vibrio nigripulchritudo, a shrimp pathogen), but this analysis also shows a greater bacterial diversity with many environmental species (Paenibacillus mucilaginosus, Actinosynnema mirum, Bacillus halodurans, ...). This 
suggests that zinc or metal scarcity is not only important at the host-pathogen interface but must also prevail in some other environments such as the soil or marine habitats.

As noted above, there are clear examples of bacteria clustering with eukaryotes. Among them, there are mainly species isolated from direct eukaryotic environment such as Jiangella alba, isolated from the stem of Maytenus austroyunnanensis, ${ }^{64}$ or Pseudoalteromonas ulvae isolated from the surface of a marine algea. ${ }^{65}$ There are also some species isolated from the soil such as Nocardioides luteus, ${ }^{66}$ Sorangium cellulosum, ${ }^{67}$ Jiangella alkaliphila isolated from a natural cave, ${ }^{68}$ or Pseudonocardia autotrophica isolated from an eucalyptus forest soil. ${ }^{69}$ Therefore, it seems that the bacteria that are grouped with the eukaryotes in the SSN may share the same ecological niche as plants and fungi, which suggests that horizontal gene transfer (HGT) may have contributed to NAS/CntL evolution and diversity in this case. Similarly, there are also clear examples of bacterial NAS/CntL gene clustering with archaeal species. These are mainly Desulfobacteraceae known to be strictly anaerobic, either mesophilic or psychrophilic sulfate-reducing, ${ }^{70}$ DeltaProteobacterium NaphS2, another sulfate-reducing bacterium, ${ }^{71}$ or Syntrophaceticus schinkii, a mesophilic, syntrophic acetate-oxidizing bacterium isolated from sludge from a mesophilic methanogenic digestor. ${ }^{72}$ Because of their physiological abilities and their habitats, these bacteria might share the same ecological niches with the archaea, as mentioned for bacteria clustered with the eukaryotes. Here as well, we hypothesize that HGT had occurred and thus participated in the evolution of the NAS/CntL family.

\section{Synteny around the NAS/cntL gene}

One other advantage of using clustering tools to analyze a particular family of protein is that we can quickly evaluate the genomic neighborhood. ${ }^{73}$ This is informative in the case of bacteria and archaea as genes are usually clustered in operonic structures with a functional unity. In the case of the NAS/CntL family, the neighborhood could be quickly assessed within each cluster identified in the SSN analysis (Figure 4B). This reveals for example that cluster 1 is homogeneous and contains almost the same cluster architecture as the one identified in $S$. aureus, which is not true for the other clusters. However, although very informative and rather fast, this analysis averages the neighborhood and may hide some exquisite details, some of them being described below.

\section{In bacteria}

In bacteria that are not regrouped with eukaryotes in our SSN, the NAS/cntL gene is found in many different species from various environments. This cntL gene, coding for the core protein in the biosynthesis of nicotianamine-like metallophore, is always upstream cntM which encodes Staphylopine dehydrogenase (SDH; Figure 5). In most Gram positive bacteria, a third biosynthetic gene cntK encoding a histidine racemase is present and located upstream the $c n t L$ gene, whereas no Gram negative bacterium has been identified as possessing this gene. 


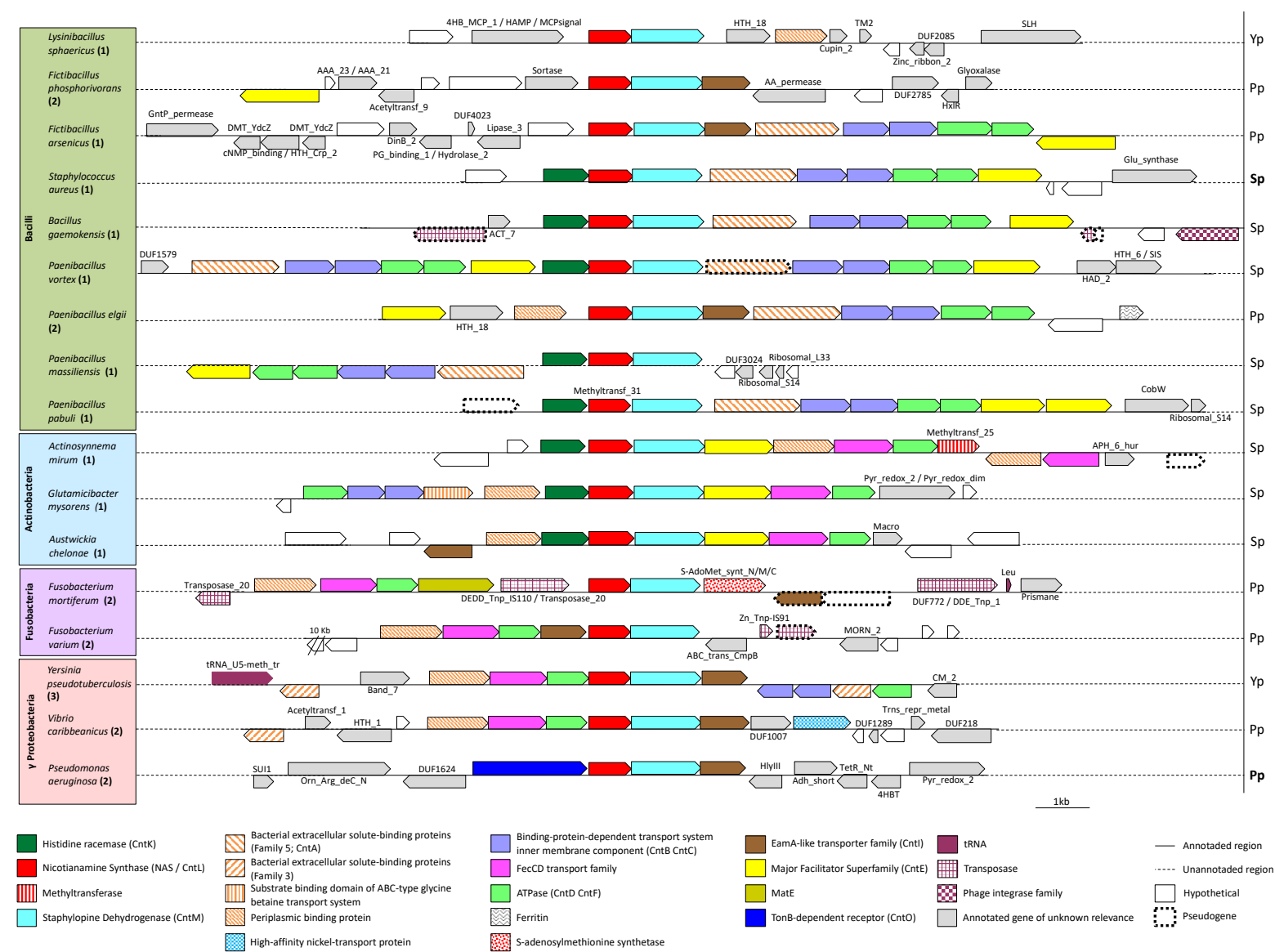

Figure 5 Diversity of the genetic organization of cnt operons in bacteria. All cht operons contain the gene coding for NAS/cntL (red) and most contain additional biosynthesis-related genes including SDH (cntM; light blue) and Histidine racemase (cntK; dark green). Most sequences contain various (metal) transport-related genes within the operon or in the regions upstream or downstream. Sp, Pp, Yp and Bp indicate a potential production of staphylopine, pseudopaline, yersinopine and bacillopaline, respectively, and as proved in some cases (in bold font) or as predicted according to the rules governing their biosynthesis (regular font). ${ }^{41}$ Numbers in bold refer to the SSN cluster to which the NAS/cntL gene belong, shown in Figure 4.

In addition to these biosynthetic genes, there are some other genes in charge of the export or import pathways. Overall, an export system is found in all bacterial operons analyzed except in L. sphaericus, which seems to only contain cntL and cntM. This might hint at an intracellular function of yersinopine in this case, although other transport genes with low sequence identity to known ones might be located elsewhere in the genome. With this one exception, species with an operon that includes the cntKLM biosynthetic system, a gene belonging to the major facilitator superfamily (MFS) is systematically found. Although this transporter family has recently been related to metal import system with YbtX in Yersinia pestis, ${ }^{74}$ this family was also found to be involved in the export of siderophores ${ }^{75,76}$ and was shown to be responsible for the export of staphylopine in S. aureus. ${ }^{35}$ Thus, the MFS transporters found in putative cnt operons are most probably involved in the export pathway of NA-like metallophores. In species with an operon lacking the $c n t K$ gene encoding the histidine racemase (i.e. producing either pseudopaline or yersinopine), a transporter belonging to EamA-like transporter family is present. In P. aeruginosa, this transporter, encoded by $c n t I$, allows the export of pseudopaline through the inner membrane. ${ }^{38}$ A third export system might be observed in Fusobacterium mortiferum in which a gene coding for a multidrug and toxic compound extrusion (MATE) efflux pump is found upstream the biosynthetic genes. This transporter is known in the export of 
antibiotics and toxic compounds, and the ability of a MATE transporter to secrete methanobactin-like compounds has been suggested. ${ }^{77}$ An interesting bacterium is Fictibacillus phosphorivorans, which is predicted to produce pseudopaline while the closest transporter belongs to an MFS transporter, although its gene is likely not included within the cnt operon (and we noted the same observation for Fictibacillus arsenicus with even closer proximity between the $c n t$ operon and the MFS gene). Whether this is purely coincidental or functional remains to be studied.

Concerning the import system, an $\mathrm{ABC}$ transporter is identified in most cnt operons sequenced. This transporter is composed of a solute-binding protein or a periplasmic binding protein, an ATPase, and a permease. Two structural organizations are observed: either one copy of a bacterial extracellular solute-binding protein associated with two copies of the permease and two copies of the ATPase, or alternatively, one copy of periplasmic binding protein with one copy of FecCD transport family (permease) and one copy of an ATPase. Furthermore, some bacteria hold additional structures with, for example, Paenibacillus vortex which possesses two copies of the $\mathrm{ABC}$ transporter with a frameshift mutation in one of the solute-binding proteins. Paenibacillus pabuli displays two copies of the MFS transporter. Actinosynnema mirum has an additional periplasmic binding protein associated with another FecCD transporter. Glutamicibacter mysorens seems to possess two transport systems, one is an ATPase with two permease and a substrate binding domain of ABC-type glycine betaine transport system and one is composed of a single copy of a solute-binding protein with a permease and an ATPase. Finally, Y. pseudotuberculosis displays a complete ABC transporter composed of two copies of a permease, one copy of an extracellular solute-binding protein and one copy of an ATPase in apparently an operon downstream the cht operon. However, it is sometimes difficult to assess whether these structures are functionally linked to the cht operon, which highlights the need of further work to better define the cnt pathway in these cases. In $P$. aeruginosa, no clear $\mathrm{ABC}$ import pathway is found within or close to the cht operon except the presence of a gene encoding for an outer membrane protein, belonging to the TonB-dependent receptor family. This gene, called cntO was shown to be involved in the import of pseudopaline-metal complexes, ${ }^{37,38}$ which therefore ask questions about how pseudopaline-metal complexes are imported in the cell, or whether only the metal is imported as it was shown for the siderophore pyoverdin in this bacterium. ${ }^{78}$ Recent data suggest that pseudopaline is modified within the periplasm, although the functional role of this modification is still not completely understood. ${ }^{58}$ Overall, we noticed that there is a plasticity in the organization of the cnt operon in bacteria, with mainly two different organizations: operons with cntKLM-E genes (mainly found in bacteria from group 1), and operons with cntLM-I genes (mainly found in bacteria from group 2 and 3). 


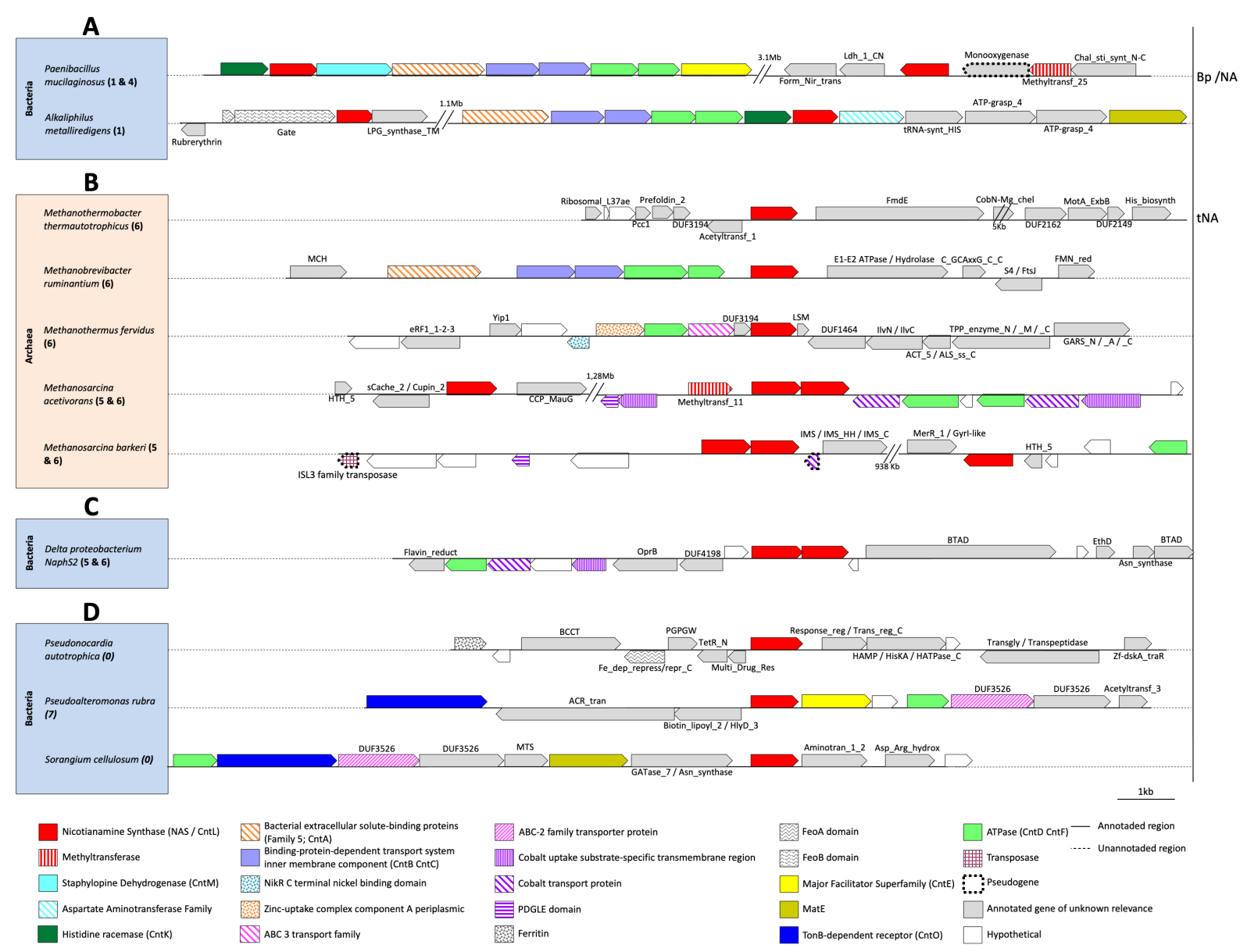

Figure 6: Atypical genomic environment around the gene coding for NAS/cntL. (A) Genetic organization of cnt operon in atypical bacteria holding two copies of NAS/cntL. (B-C) Genomic environment around the NAS/cntL in some archaea and bacteria grouped in the archaeal cluster. In archaea that carry the gene coding for NAS/cntL, there are either one or three copies of this gene (one isolated and two in tandem) while there is only a tandem copy in Delta proteobacterium NaphS2, which support a clear archaeato-bacteria horizontal gene transfer event. (D) Genomic environment around the NAS/cntL gene in some bacteria grouped in the eukaryote cluster: in eukaryotes, many species have multiple copies of the NAS gene dispersed in the genome, but there is only one copy in the related bacteria. Bp/NA indicates a potential production of bacillopaline by one cnt operon (presented on the left) and eventually nicotianamine by the second one (on the right). Both tNA and Bp/NA are predicted from biochemical works or from sequence similarities, and no evidence of their existence in vivo has yet been obtained. Numbers in bold refer to the SSN cluster(s) to which the NAS/cntL gene(s) belong and shown in Figure 4.

Except these genomic organizations, we also noticed some atypical cnt operon organizations in some bacteria. For example, P. mucilaginosus and Alkaliphilus metalliredigens possess two copies of NAS/cntL: one copy integrated in a putative cnt operon, and one copy isolated from the other (Figure 6A). The role, if any, of this second copy is not known yet. In these species, one of the cht operon is rather classical i.e. with genes related to transport system and to a biosynthetic system composed of cntKLM in the case of $P$. mucilaginosus. Interestingly, in $A$. metalliredigens an aspartate aminotransferase replaces the $c n t M$ gene, which may reflect a different nicotianaminelike metallophore production in this case. This is supported by the presence of a MATE efflux pump instead of an MFS efflux pump, which is not common in cht operons.

Interestingly, we also noticed what might be clear examples of HGT events from archaea to bacteria and from plants to bacteria. Indeed, Delta proteobacterium NaphS2, which is grouped with the archaea in the cluster 5 and 6 of the SSN, hold two tandem copies of the NAS/cntL gene, as in the cnt operon found in some archaea (compare Figure 6B and Figure 
6C). Moreover, only an ATPase and two genes related to cobalt transport are present around these two NAS. This structural organization therefore looks like the one found in archaea and described below. On the other hand, Pseudonocardia autotrophica, Pseudoalteromonas rubra and Sorangium cellulosum do cluster with eukaryotes in the SSN and possess only one copy of the NAS/cntL gene (Figure 6D). In these species, the NAS/cntL does not seem to be integrated into an operonic structure carrying the associated biosynthetic or transport systems, as is the case in the bacterial clusters 1-3 in the SSN. However, we noticed some transport-related gene in the cntL genomic environment: TonB-dependent receptor, MFS and ATPase in P. rubra; TonB-dependent receptor and MATE in S. cellulosum. These genetic organizations, combined with the fact that these species share a same ecological niche with plants, suggest HGT events by transformation between plants and bacteria.

A final remark is that there are some evidences for the presence of transposases around the cht operons in some bacteria like Bacillus gaemokensis and Fusobacterium mortiferum. These transposases may be evidence of HGT by transduction which could be involved in the evolution of the cnt pathway as mentioned above. Overall, the diversity of cnt operonic structure organizations highlighted above should fuel future wet-lab studies uncovering novel nicotianamine-like metallophores and might uncover new metallophore functions.

\section{In archaea}

In archaea, the NAS/cntL gene is either found as a single copy like in Methanobrevibacter ruminantium, Methanothermus fervidus or Methanothermus thermautotrophicus, or in triplicate like in Methanosarcica acetivoran (Figure 6B). In this archaea, one copy is isolated from the two others which are located in tandem. Interestingly, several species belonging to the Methanosarcina genus possess this same arrangement, as found in $M$. barkeri, M. vacuolata, M. siciliae and M. mazei. Looking their position in the SSN, we noticed that one copy of the two NAS/cntL sequences found in tandem is located in the subgroup 5, whereas the two others are clustered in the subgroup 6. Another operonic structure containing two copies of truncated NAS has been observed in Methanobrevibacter smithii and Methanothermobacter marburgensis, which asks question whether these proteins are functional or not. Concerning the transport system, no gene related to export system is located close to the NAS/cntL gene. However, genes involved in the import are observed, with a complete ABC transporter (Permease, ATPase together with a periplasmic binding protein) in M. ruminantium and M. fervidus, for which there is a clear homology to characterized zinc and nickel transporters. ${ }^{79,80}$ A question to be attempted to answer in the future will therefore be whether this NAS gene is involved in zinc homeostasis in this organism. Some genes involved in cobalt uptake are associated with two ATPases in M. acetivorans, which might link cobalt transport with NA, tNA or another nicotianamine-like metallophore. In M. thermautotrophicus, no NA-like transport system has been found. Although initial results showed that tNA has a strong affinity for $\mathrm{Ni}$ and $\mathrm{Cu}$, no in vivo studies have been carried out. Overall, there is still no in vivo evidence for a nicotianamine-like system in the uptake of metals in archaea, which is certainly due to the difficulties to obtain mutants and study metal transport in their often-complex growth media.

\section{Evolutionary history of NAS/CntL}

SSN of NAS/CntL sequences revealed that eukaryote protein sequences are well separated from archaeal and bacterial sequences, with a few probable examples of HGT events described above. This clustering hints to an ancient origin of this protein, which 
would have appeared before the separation of these three kingdoms. Alternatively, an HGT event may have been old enough so as to happen before the diversification of bacteria that do possess a NAS/cntL gene. Another alternative is that HGT prevail within each kingdom and the overall separation of the NAS/CntL is fortuitous. In order to better understand the evolutionary mechanisms of the NAS/CntL family, we constructed and compared a molecular phylogenetic analysis of the nucleotide sequences coding for the $16 \mathrm{~S}$ rDNA of bacteria with the one of NAS/CntL from the same species (Figure 7A-B). Comparing the two trees suggests a congruence of the 16S rDNA and NAS/CntL trees as they show the same overall topology, with four distinct clusters (Bacilli, Actinobacteria, Fusobacteria and $\gamma$-proteobacteria) and an overall clustering of Gram positive and Gramnegative bacteria. However, Actinobacteria are found with Bacilli in the tree of NAS, resulting in a paraphyletic group. More interestingly, some Bacilli (Fictibacillus phosphorivorans, F. arsenicus and Paenibacillus elgii) clustered with the $\gamma$-proteobacteria in the same tree suggesting a HGT in this case. This is supported by the genetic neighborhood analysis showing that, contrary to other Bacilli that possess a CntE homologue for metallophore export, these bacteria instead possess a CntI homologue. A phylogeny based on CntM amino acid sequences from the same species clearly indicates that CntL and CntM co-evolved, further supporting this HGT event (Figure S1). 


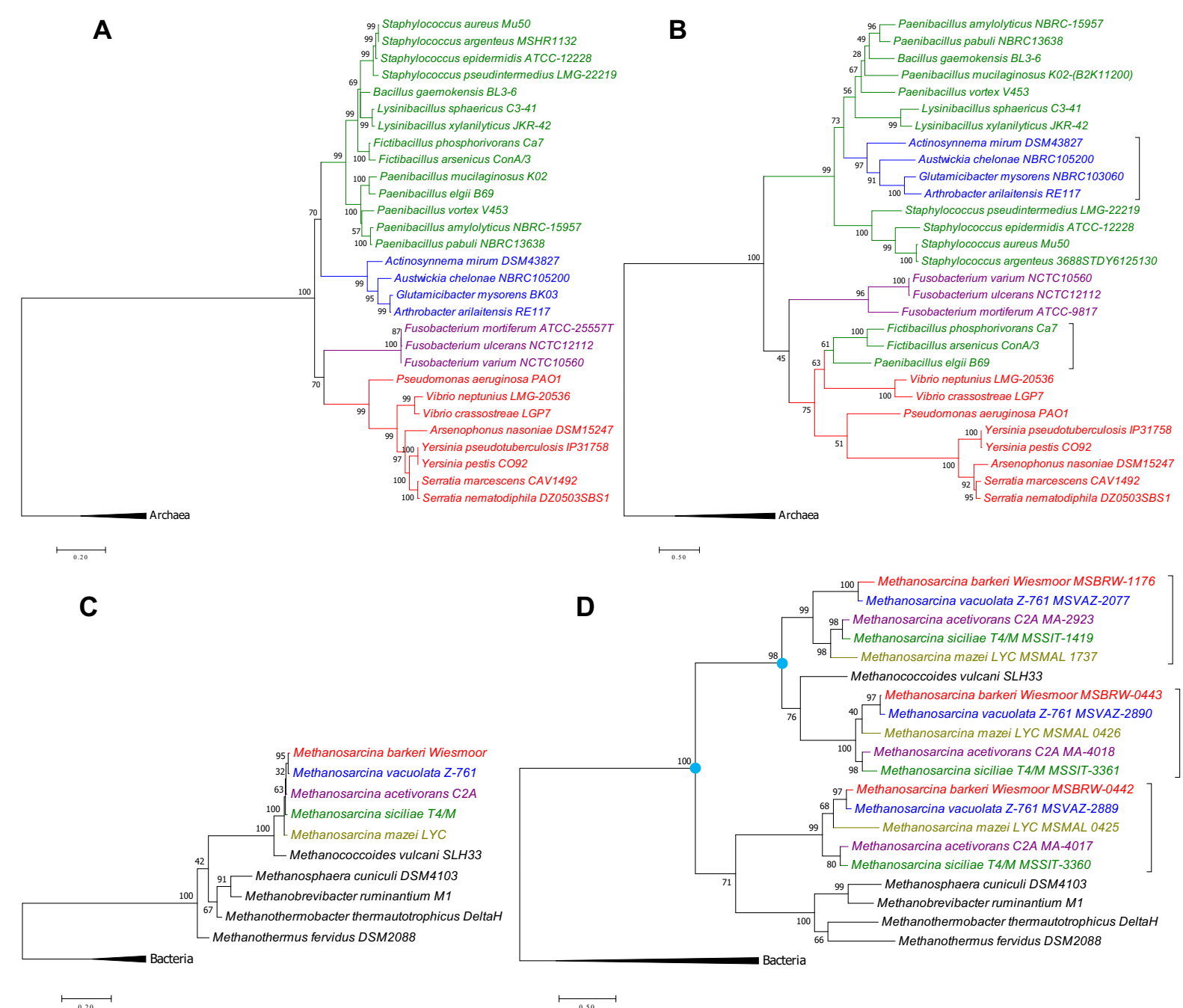

Figure 7 Molecular phylogenetic analyses of the NAS/CntL and comparison with 16S evolution. Phylogenetic tree of 16S rDNA (A and C) and NAS/CntL amino acid sequences from bacteria (B) and archaea (D). Theses evolutionary trees were constructed in MEGA 7.0.26 by using the Maximum Likelihood Method. They were based on a MUSCLE alignment and on best models chosen according to the Bayesian Information Criterion (BIC). The percentage of trees in which the associated taxa clustered together is shown next to the branches. The evolutionary history of the 16S rDNA (panels A and C) was inferred by using the General Time Reversible model with a discrete Gamma distribution. The rate variation model allowed for some sites to be evolutionarily invariable. The evolutionary history of the NAS/CntL trees (panels B and D) was inferred by using the LG (Le_Gascuel) model with a discrete Gamma distribution. The rate variation model allowed for some sites to be evolutionarily invariable. Number of bootstrap replications $=1000$. Bacilli, Actinobacteria, Fusobacteria and $\gamma$-proteobacteria are depicted in green, blue, violet and red, respectively. The blue circles in panel D indicate probable gene duplication events leading to three NAS/cntL genes.

The same comparison between the 16 rDNA and NAS/CntL in the domain of archaea revealed the duplication events involved in the evolutionary history of this family (Figure 7 C-D). Indeed, most of the archaea having a NAS/cntL gene homologue possess in fact three copies, two in tandem and one in a separate environment. The phylogenetic tree shows this triplication event, with the same pattern repeated three time (for each copies) suggesting two duplication events. Because each subtree is congruent with the 16S rDNA tree, we concluded that the acquisition of the NAS/CntL predates the diversification of this branch of archaea. 


\section{Metals and the origin of life}

Our origins and the origin of life have always attracted our attention and is a matter of interesting hypothesis and fierce debates. Paying particular attention to the role of micronutrients (mainly $\mathrm{Mn}, \mathrm{Fe}, \mathrm{Co}, \mathrm{Ni}, \mathrm{Cu}$ and $\mathrm{Zn}$ ) in the emergence of life, it can be argued that these metals must have been present in the early cells in order to sustain the beginning of life. This view is supported by the large number (approximately 1/3) of nowadays proteins that require a metal to fold or function and the numerous biological pathways requiring at least one metalloprotein. ${ }^{81,82}$ This question of the metal status in the origin of life is interesting in many aspects and one study suggests that life emerged from terrestrial anoxic geothermal fields where there is a high $\mathrm{K}^{+} / \mathrm{Na}^{+}$ratio and a high concentration of $\mathrm{Zn}^{2+}, \mathrm{Mn}^{2+}$ and phosphate ions. ${ }^{83}$ All these conditions are considered favorable because the history of proteins that could be traced back to the last universal common ancestor (LUCA) show the same metal preference. ${ }^{84,85}$ Changes in the availability of essential micronutrients may then have shaped the evolution of life on earth. ${ }^{86}$ Protocells, which most arguably existed without an ion-tight membrane and its arsenal of membrane ion transporters, would have therefore appeared in this type of micronutrient rich habitat. This is supported by Krebs-like cycle observed in a purely chemical reaction network promoted by ferrous iron. ${ }^{87}$ However, one question is therefore how to escape from these favorable niches and to reach metal scarce environments like the marine seawater, where the concentration of these micronutrients would supposedly drops abruptly. Scavenging of essential metal ions through ABC transporter may have evolved early, as supported by their early appearance in folded families. ${ }^{88}$ Unfortunately, not much is known about the history of metallochaperones or other proteins involved in the synthesis of metallophores. NRPS is an old fold family and responsible for the synthesis of many different factors like antibiotics, channel forming peptides but also some siderophores. ${ }^{88}$ NRPS might have therefore been used for the synthesis of metallophores that were used for metal acquisition or resistance. In the history of siderophores, a plausible scenario has been described in which the entire system would have evolved in two stages: first, the biosynthesis of siderophores, useful to prevent iron intoxication when iron was highly available, i.e. before the rise of oxygen level on earth, and second, the implementation of receptors to ensure the siderophore-iron uptake when this micronutrient drastically decreased due to its precipitation in the oxidized form. ${ }^{89}$ Here we also argue that NAS/CntL is an ancient protein that might have participate in this early metal resistance/scavenging history. Indeed, it might have evolved first as an $\mathrm{Fe}^{2+} / \mathrm{Zn}^{2+}$ metallophore involved in the resistance to the high concentration of metals that prevailed in early earth history. The decrease in the concentration of these metals after the great oxidation event would explain the fact that the $N A S / c n t L$ gene was only kept in specific niches with metal scarce conditions, such as at the host-pathogen interface or in some soils. In these environments other genes involved in metallophore secretion and metalmetallophore acquisition would have been acquired to adapt to metal acquisition in these niches. Whether this trend is correlated to the availability of $\mathrm{Zn}^{2+}$ through time, which was scarce until the rise of oxygen level, or iron, which followed an opposite trend 86 remains an open question.

\section{Conclusions}

The discovery of a nicotianamine-like metallophore in $S$. aureus has led to the discovery of new metal acquisition pathways in several bacteria. These systems function like siderophores, with the synthesis of the metallophore, its export in the extracellular space and the recovery of metals or metal-metallophore complexes. In $P$. aeruginosa and $S$. 
aureus, these systems are involved in the uptake of essential micronutrients, with metal uptake efficiencies that depend on the chelating force of the growth media. Zinc is a common metal that is acquired by these systems, which is in line with their regulation by Zur in both bacteria. However, Fur is also a regulator of this pathway in S. aureus, which may be an indication that this metal is also a target of staphylopine, most probably in its reduced form. ${ }^{35,61} \mathrm{In}$ fact, this was hinted in the initial discovery of staphylopine, and the recent finding of an interplay between iron starvation and zinc uptake in P. aeruginosa, including the pseudopaline pathway, suggests a conserved link between iron and zinc. ${ }^{90}$ The diversity of nicotianamine-like metallophores is so far limited to four different metallophores in bacteria and the rules governing their biosynthesis had been established. However, based on our analysis of cnt pathways synteny, there is no doubt that further diversity will be revealed in the future. Particularly, the high plasticity found in the genomic organization of the cnt operons in bacteria and archaea opens the door to multiple and different roles of these metallophores in metal uptake or resistance strategies. Following the homology between NA-like metallophores and siderophores, discovery of novel NA-like functions are anticipated, such as cheating behaviors, when one non-producing specie beneficiates from another metallophore-producing specie, competition, or cooperation when metallophore production provides direct benefits to both the producers and the recipients. ${ }^{89,91,92}$ Metallophore perception can also serve as a signal for triggering protection systems like sporulation. ${ }^{93}$ Recently, it has been showed that nicotianamine helped in maintaining symbiotic nitrogen fixation in Medicago truncatula nodules, demonstrating a role of this metallophore in cross-species interaction and symbiosis. ${ }^{15}$ The recent discovery of nicotianamine-like metallophores in bacteria now paves the way for detection of novel functions other than the ones limited to metal uptake strategies.

\section{Acknowledgements}

We would like to thank the long-term support of D. Pignol (CEA, France) as well as several collaborators who have allowed the discovery and characterization of NA-like metallophores in bacteria: E. Borezée-Durant, (INRAE, France), R. Lobinski and L. Ouerdane (UPPA, France), R. Voulhoux (CNRS, France) and F. Cavelier (CNRS, France). C. Brutesco is also acknowledged for her benchwork in this project, and J. Lavergne for his intellectual and stimulating inputs. We also thank E. Borezée-Durant, L. Ouerdane, R. Voulhoux and M. Siponen (CNRS, France) for the reading of this review. The works on metallophores was initially supported by the ANR (ANR-14-CE09-0007) and by the associations "Vaincre la Mucoviscidose" (grant 20160501495) and "Gregory Lemarchal". P. A. wish to dedicate this review to the memory of C. Wandersman for her mentoring and her ability to transmit the love of science. 


\section{References}

1 M. Noma, M. Noguchi and E. Tamaki, Tetrahedron Letters, 1971, 12, 2017-2020.

2 I. Kristensen and P. O. Larsen, Phytochemistry, 1974, 13, 2791-2798.

3 M. Buděšínský, H. Budzikiewicz, Ž. Procházka, H. Ripperger, A. Römer, G. Scholz and K. Schreiber, Phytochemistry, 1980, 19, 2295-2297.

4 Ž. Procházka and G. Scholz, Experientia, 1984, 40, 794-801.

5 C. Curie, G. Cassin, D. Couch, F. Divol, K. Higuchi, M. Le Jean, J. Misson, A. Schikora, P. Czernic and S. Mari, Annals of Botany.

6 N. von Wiren, S. Klair, S. Bansal, J.-F. Briat, H. Khodr, T. Shioiri, R. A. Leigh and R. C. Hider, Plant Physiol., 1999, 119, 1107-1114.

7 I. Beneš, K. Schreiber, H. Ripperger and A. Kircheiss, Experientia, 1983, 39, 261-262.

8 S. M. Reichman and D. R. Parker, Plant Physiol, 2002, 129, 1435-1438.

9 A. Pich, G. Scholz and U. W. Stephan, Biometals, 1994, 165, 189-196.

10 M. Takahashi, Y. Terada, I. Nakai, H. Nakanishi, E. Yoshimura, S. Mori and N. K. Nishizawa, Plant Cell, 2003, 102561.

11 U. Deinlein, M. Weber, H. Schmidt, S. Rensch, A. Trampczynska, T. H. Hansen, S. Husted, J. K. Schjoerring, I. N. Talke, U. Krämer and S. Clemens, Plant Cell, 2012, 24, 708-723.

12 M. J. Haydon, M. Kawachi, M. Wirtz, S. Hillmer, R. Hell and U. Krämer, Plant Cell, 2012, 24, 724-737.

13 S. Mari, D. Gendre, K. Pianelli, L. Ouerdane, R. Lobinski, J.-F. Briat, M. Lebrun and P. Czernic, J Exp Bot, 2006, 57, 4111-4122.

14 M. Klatte, M. Schuler, M. Wirtz, C. Fink-Straube, R. Hell and P. Bauer, Plant Physiol., $2009,150,257-271$.

15 V. Escudero, I. Abreu, E. del Sastre, M. Tejada-Jiménez, C. Larue, L. Novoa-Aponte, J. Castillo-González, J. Wen, K. S. Mysore, J. Abadía, J. M. Argüello, H. Castillo-Michel, A. Álvarez-Fernández, J. Imperial and M. González-Guerrero, Front. Plant Sci., , DOI:10.3389/fpls.2019.01780.

16 M. Weber, E. Harada, C. Vess, E. Roepenack-Lahaye and S. Clemens, The Plant Journal, 2004, 37, 269-281.

17 S. Kim, M. Takahashi, K. Higuchi, K. Tsunoda, H. Nakanishi, E. Yoshimura, S. Mori and N. K. Nishizawa, Plant Cell Physiol., 2005, 46, 1809-1818.

18 K. Pianelli, S. Mari, L. Marquès, M. Lebrun and P. Czernic, Transgenic Res., 2005, 14, 739-748.

19 S. Lee, U. S. Jeon, S. J. Lee, Y.-K. Kim, D. P. Persson, S. Husted, J. K. Schjørring, Y. Kakei, H. Masuda, N. K. Nishizawa and G. An, Proceedings of the National Academy of Sciences, 
2009, 106, 22014-22019.

20 S. Lee, Y.-S. Kim, U. S. Jeon, Y.-K. Kim, J. K. Schjoerring and G. An, Mol. Cells, 2012, 33, 269-275.

21 J. Wirth, S. Poletti, B. Aeschlimann, N. Yakandawala, B. Drosse, S. Osorio, T. Tohge, A. R. Fernie, D. Günther, W. Gruissem and C. Sautter, Plant Biotechnol. J., 2009, 7, 631644.

22 T.-Y. Wu, W. Gruissem and N. K. Bhullar, Plant Biotechnol. J., , DOI:10.1111/pbi.12943.

23 T. Nozoye, Front Plant Sci, 2018, 9, 340.

24 C. Curie, Z. Panaviene, C. Loulergue, S. L. Dellaporta, J. F. Briat and E. L. Walker, Nature, 2001, 409, 346-349.

25 E. P. Colangelo and M. L. Guerinot, Curr. Opin. Plant Biol., 2006, 9, 322-330.

26 D. Gendre, P. Czernic, G. Conéjéro, K. Pianelli, J.-F. Briat, M. Lebrun and S. Mari, Plant J., 2007, 49, 1-15.

27 A. Herbik, G. Koch, H. P. Mock, D. Dushkov, A. Czihal, J. Thielmann, U. W. Stephan and H. Bäumlein, Eur. J. Biochem., 1999, 265, 231-239.

28 K. Higuchi, K. Suzuki, H. Nakanishi, H. Yamaguchi, N. K. Nishizawa and S. Mori, Plant Physiology, 1999, 119, 471-480.

29 H. Q. Ling, G. Koch, H. Bäumlein and M. W. Ganal, Proc. Natl. Acad. Sci. U.S.A, 1999, 96, 7098-7103.

30 A. Trampczynska, C. B \öttcher and S. Clemens, FEBS letters, 2006, 580, 3173-3178.

31 S. A. Rensing, D. Lang, A. D. Zimmer, A. Terry, A. Salamov, H. Shapiro, T. Nishiyama, P.F. Perroud, E. A. Lindquist, Y. Kamisugi, T. Tanahashi, K. Sakakibara, T. Fujita, K. Oishi, T. Shin-I, Y. Kuroki, A. Toyoda, Y. Suzuki, S.-I. Hashimoto, K. Yamaguchi, S. Sugano, Y. Kohara, A. Fujiyama, A. Anterola, S. Aoki, N. Ashton, W. B. Barbazuk, E. Barker, J. L. Bennetzen, R. Blankenship, S. H. Cho, S. K. Dutcher, M. Estelle, J. A. Fawcett, H. Gundlach, K. Hanada, A. Heyl, K. A. Hicks, J. Hughes, M. Lohr, K. Mayer, A. Melkozernov, T. Murata, D. R. Nelson, B. Pils, M. Prigge, B. Reiss, T. Renner, S. Rombauts, P. J. Rushton, A. Sanderfoot, G. Schween, S.-H. Shiu, K. Stueber, F. L. Theodoulou, H. Tu, Y. Van De Peer, P. J. Verrier, E. Waters, A. Wood, L. Yang, D. Cove, A. C. Cuming, M. Hasebe, S. Lucas, B. D. Mishler, R. Reski, I. V. Grigoriev, R. S. Quatrano and J. L. Boore, Science, 2008, 319, 64-69.

32 C. Dreyfus, D. Pignol and P. Arnoux, Acta Crystallographica Section F, 2008, 64, 933935.

33 C. Dreyfus, D. Lemaire, S. Mari, D. Pignol and P. Arnoux, Proceedings of the National Academy of Sciences, 2009, 106, 16180-16184.

34 C. Dreyfus, M. Larrouy, F. Cavelier, J. Martinez, D. Pignol and P. Arnoux, Chem. Commun. (Camb.), 2011, 47, 5825-5827.

35 G. Ghssein, C. Brutesco, L. Ouerdane, C. Fojcik, A. Izaute, S. Wang, C. Hajjar, R. Lobinski, 
D. Lemaire, P. Richaud, R. Voulhoux, A. Espaillat, F. Cava, D. Pignol, E. Borezee-Durant and P. Arnoux, Science, 2016, 352, 1105-1109.

36 J. Thompson and J. A. Donkersloot, Annu. Rev. Biochem., 1992, 61, 517-557.

37 M. C. Mastropasqua, M. D’Orazio, M. Cerasi, F. Pacello, A. Gismondi, A. Canini, L. Canuti, A. Consalvo, D. Ciavardelli, B. Chirullo, P. Pasquali and A. Battistoni, Mol. Microbiol., , DOI:10.1111/mmi.13834.

38 S. Lhospice, N. O. Gomez, L. Ouerdane, C. Brutesco, G. Ghssein, C. Hajjar, A. Liratni, S. Wang, P. Richaud, S. Bleves, G. Ball, E. Borezée-Durant, R. Lobinski, D. Pignol, P. Arnoux and R. Voulhoux, Sci Rep, 2017, 7, 17132.

39 J. S. McFarlane and A. L. Lamb, Biochemistry, 2017, 56, 5967-5971.

40 J. S. McFarlane, C. L. Davis and A. L. Lamb, J. Biol. Chem., 2018, 293, 8009-8019.

41 C. Laffont, C. Brutesco, C. Hajjar, G. Cullia, R. Fanelli, L. Ouerdane, F. Cavelier and P. Arnoux, Biochem. J., 2019, 476, 2221-2233.

42 S. Luo, Y. Ju, J. Zhou, Q. Gu, J. Xu and H. Zhou, Int. J. Biol. Macromol., 2019, 135, 725733.

43 C. Hajjar, R. Fanelli, C. Laffont, C. Brutesco, G. Cullia, M. Tribout, D. Nurizzo, E. BorezéeDurant, R. Voulhoux, D. Pignol, J. Lavergne, F. Cavelier and P. Arnoux, J. Am. Chem. Soc., $2019,141,5555-5562$.

44 R. E. Marsh and D. A. Clemente, Inorganica Chimica Acta, 2007, 360, 4017-4024.

45 Y. Mino, T. Ishida, N. Ota, M. Inoue, K. Nomoto, T. Takemoto, H. Tanaka and Y. Sugiura, J. Am. Chem. Soc., 1983, 105, 4671-4676.

46 L. Song, Y. Zhang, W. Chen, T. Gu, S.-Y. Zhang and Q. Ji, Proc. Natl. Acad. Sci. U.S.A., 2018, 115, 3942-3947.

47 L. Remy, M. Carrière, A. Derré-Bobillot, C. Martini, M. Sanguinetti and E. BorezéeDurant, Molecular Microbiology, 2013, 87, 730-743.

48 K. P. Grim, B. San Francisco, J. N. Radin, E. B. Brazel, J. L. Kelliher, P. K. Párraga Solórzano, P. C. Kim, C. A. McDevitt and T. E. Kehl-Fie, MBio, , DOI:10.1128/mBio.01281-17.

49 Y. Ding, Y. Fu, J. C. Lee and D. C. Hooper, J. Bacteriol., 2012, 194, 6586-6593.

50 C. Chen and D. C. Hooper, FEBS Lett., 2019, 593, 1213-1222.

51 K. P. Grim, J. N. Radin, P. K. P. Solórzano, J. R. Morey, K. A. Frye, K. Ganio, S. L. Neville, C. A. McDevitt and T. E. Kehl-Fie, Journal of Bacteriology, , DOI:10.1128/JB.00014-20.

52 P. Bielecki, J. Puchałka, M. L. Wos-Oxley, H. Loessner, J. Glik, M. Kawecki, M. Nowak, B. Tümmler, S. Weiss and V. A. P. M. dos Santos, PLoS ONE, 2011, 6, e24235.

53 M. Gi, K.-M. Lee, S. C. Kim, J.-H. Yoon, S. S. Yoon and J. Y. Choi, Sci Rep, 2015, 5, 1-15.

54 J. Zhang, S. Wang, Y. Bai, Q. Guo, J. Zhou and X. Lei, J. Org. Chem., 2017, 82, 13643- 
13648.

55 J. S. McFarlane, J. Zhang, S. Wang, X. Lei, G. R. Moran and A. L. Lamb, J. Biol. Chem., 2019, 294, 17988-18001.

56 J. Zhang, T. Zhao, R. Yang, I. Siridechakorn, S. Wang, Q. Guo, Y. Bai, H. C. Shen and X. Lei, Chem. Sci., 2019, 10, 6635-6641.

57 G. Cullia, R. Fanelli, R. Voulhoux, P. Arnoux and F. Cavelier, European Journal of Organic Chemistry, , DOI:10.1002/ejoc.202000278.

58 N. O. Gomez, A. Tetard, L. Ouerdane, C. Laffont, C. Brutesco, G. Ball, R. Lobinski, Y. Denis, P. Plésiat, C. Llanes, P. Arnoux and R. Voulhoux, bioRxiv, 2020, 2020.05.13.092411.

59 J.-W. Lee and J. D. Helmann, Biometals, 2007, 20, 485-499.

60 V. G. Pederick, B. A. Eijkelkamp, S. L. Begg, M. P. Ween, L. J. McAllister, J. C. Paton and C. A. McDevitt, Scientific Reports, 2015, 5, 13139.

61 C. Fojcik, P. Arnoux, L. Ouerdane, M. Aigle, L. Alfonsi and E. Borezée-Durant, Mol. Microbiol., 2018, 108, 159-177.

62 J. A. Gerlt, J. T. Bouvier, D. B. Davidson, H. J. Imker, B. Sadkhin, D. R. Slater and K. L. Whalen, Biochim. Biophys. Acta, 2015, 1854, 1019-1037.

63 P. Shannon, A. Markiel, O. Ozier, N. S. Baliga, J. T. Wang, D. Ramage, N. Amin, B. Schwikowski and T. Ideker, Genome Res., 2003, 13, 2498-2504.

64 S. Qin, G.-Z. Zhao, J. Li, W.-Y. Zhu, L.-H. Xu and W.-J. Li, International Journal of Systematic and Evolutionary Microbiology, 2009, 59, 2162-2165.

65 S. Egan, S. Kjelleberg and C. Holmström, International Journal of Systematic and Evolutionary Microbiology, 2001, 51, 1499-1504.

66 H. Prauser, Zeitschrift für allgemeine Mikrobiologie, 2007, 24, 647-648.

67 J. R. Lampky, Applied Microbiology, 1971, 22, 937-938.

68 S. D. Lee, International Journal of Systematic and Evolutionary Microbiology, 2008, 58, 1176-1179.

69 T. Okazaki, N. Serizawa, R. Enokita, A. Torikata and A. Terahara, The Journal of Antibiotics, 1983, 36, 1176-1183.

70 J. Kuever, in The Prokaryotes: Deltaproteobacteria and Epsilonproteobacteria, eds. E. Rosenberg, E. F. DeLong, S. Lory, E. Stackebrandt and F. Thompson, Springer, Berlin, Heidelberg, 2014, pp. 45-73.

71 A. Galushko, D. Minz, B. Schink and F. Widdel, Environ. Microbiol., 1999, 1, 415-420.

72 M. Westerholm, S. Roos and A. Schnürer, FEMS Microbiol. Lett., 2010, 309, 100-104.

73 R. Zallot, N. O. Oberg and J. A. Gerlt, Curr Opin Chem Biol, 2018, 47, 77-85. 
74 A. G. Bobrov, O. Kirillina, M. Y. Fosso, J. D. Fetherston, M. C. Miller, T. T. VanCleave, J. A. Burlison, W. K. Arnold, M. B. Lawrenz, S. Garneau-Tsodikova and R. D. Perry, Metallomics, 2017, 9, 757-772.

75 T. J. Brickman and S. K. Armstrong, Journal of Bacteriology, 2005, 187, 3650-3661.

76 J. L. Furrer, D. N. Sanders, I. G. Hook-Barnard and M. A. McIntosh, Molecular Microbiology, 2002, 44, 1225-1234.

77 G. E. Kenney and A. C. Rosenzweig, BMC Biology, 2013, 11, 17.

78 I. J. Schalk, M. A. Abdallah and F. Pattus, Biochemistry, 2002, 41, 1663-1671.

79 Y. H. Lee, R. K. Deka, M. V. Norgard, J. D. Radolf and C. A. Hasemann, Nat. Struct. Biol., $1999,6,628-633$.

80 B. Wei, A. M. Randich, M. Bhattacharyya-Pakrasi, H. B. Pakrasi and T. J. Smith, Biochemistry, 2007, 46, 8734-8743.

81 A. C. Rosenzweig, Chem. Biol., 2002, 9, 673-677.

82 K. J. Waldron, J. C. Rutherford, D. Ford and N. J. Robinson, Nature, 2009, 460, 823-830.

83 A. Y. Mulkidjanian, A. Y. Bychkov, D. V. Dibrova, M. Y. Galperin and E. V. Koonin, PNAS, 2012, 109, E821-E830.

84 C. L. Dupont, A. Butcher, R. E. Valas, P. E. Bourne and G. Caetano-Anollés, Proc Natl Acad Sci U S A, 2010, 107, 10567-10572.

85 A. Y. Mulkidjanian and M. Y. Galperin, Proc. Natl. Acad. Sci. U.S.A., 2010, 107, E137; author reply E138.

86 A. D. Anbar, Science, 2008, 322, 1481-1483.

87 K. B. Muchowska, S. J. Varma and J. Moran, Nature, 2019, 569, 104-107.

88 G. Caetano-Anollés, K. M. Kim and D. Caetano-Anollés, Journal of Molecular Evolution, $2012,74,1-34$.

89 J. Kramer, Ö. Özkaya and R. Kümmerli, Nat. Rev. Microbiol., 2020, 18, 152-163.

90 C. E. Nelson, W. Huang, L. K. Brewer, A. T. Nguyen, M. A. Kane, A. Wilks and A. G. Oglesby-Sherrouse, J. Bacteriol., , DOI:10.1128/JB.00754-18.

91 T. Julou, T. Mora, L. Guillon, V. Croquette, I. J. Schalk, D. Bensimon and N. Desprat, Proc. Natl. Acad. Sci. U.S.A., 2013, 110, 12577-12582.

92 K. T. Schiessl, A. Ross-Gillespie, D. M. Cornforth, M. Weigert, C. Bigosch, S. P. Brown, M. Ackermann and R. Kümmerli, Evolution, 2019, 73, 675-688.

93 G. M. Grandchamp, L. Caro and E. A. Shank, Appl. Environ. Microbiol., , DOI:10.1128/AEM.03293-16.

94 I. Benes, H. Ripperger and A. Kircheiss, Experientia, 1983, 39, 261-262. 
95 D. C. Harris, Quantitative Chemical Analysis, W. H. Freeman and Company, 8th Edition., 2010. 


\section{Supplementary Figures}

A

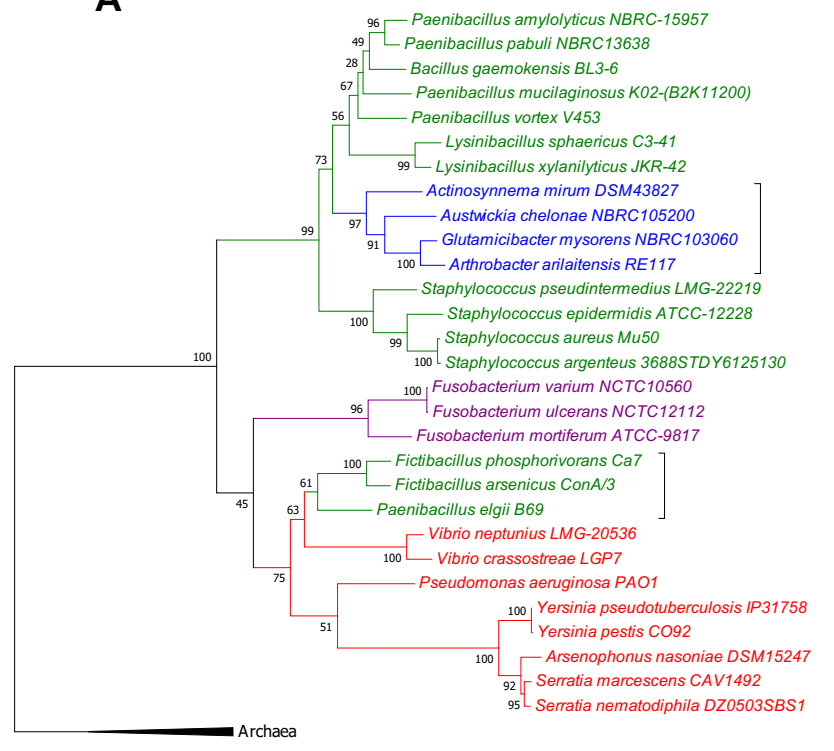

B

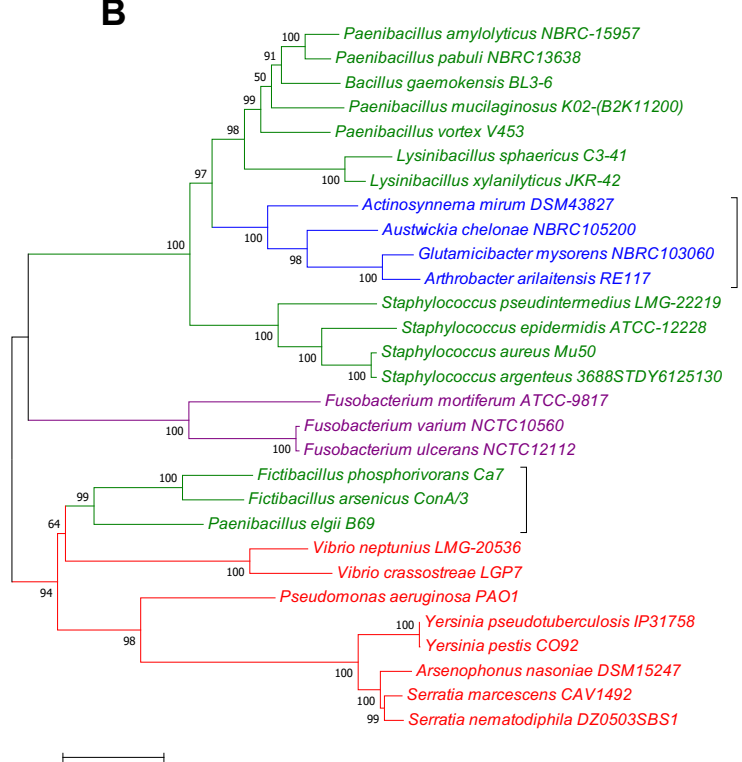

Supplementary Figure 1: Molecular phylogenetic analyses of diverse CntL alone (A) and CntLM (B) amino acid sequences from bacteria. Theses evolutionary trees were constructed in MEGA 7.0.26 by using the Maximum Likelihood Method. They were based on a MUSCLE alignment and on best models chosen according to the Bayesian Information Criterion (BIC). The percentage of trees in which the associated taxa clustered together is shown next to the branches. The evolutionary history was inferred by using the LG (Le_Gascuel) model with a discrete Gamma distribution. The rate variation model allowed for some sites to be evolutionarily invariable. Number of bootstrap replications $=1000$. Bacilli, Actinobacteria, Fusobacteria and $\gamma$-proteobacteria are depicted in green, blue, violet and red, respectively. 